\title{
刺激响应介孔氧化硅纳米载药系统的可控组装及 控制释放性能
}

\author{
杜学忠 \\ 南京大学化学化工学院, 介观化学教育部重点实验室, 南京 210023 \\ E-mail: xzdu@nju.edu.cn \\ 2016-04-05 收稿, 2016-05-06 修回, 2016-05-11 接受, 2016-07-11 网络版发表 \\ 国家自然科学基金(21273112)资助
}

\begin{abstract}
摘要刺激响应介孔氧化硅纳米载药系统能够有效提高药物的治疗效果和尽量降低药物的毒副作用, 相关研究 领域近年来引起人们的极大关注. 本文主要介绍作者课题组在阀控和门控的介孔氧化硅纳米载药系统的研究工 作. 以生物相容性的介孔氧化硅纳米粒子(MSN)作为药物载体, 将端基为活性基团的硅烷自组装修饰在MSN表面, 并进一步功能化, 通过多重弱键相互作用、动态共价键甚至和强共价键, 将大环主体化合物、蛋白、DNA和量子 点等结合到MSN表面, 将药物封装在MSN孔道内, 构成纳米阀和纳米门. 可控组装的阀控和门控的MSN纳米载药 系统, 在 $\mathrm{pH}$ 、氧化还原、竞争结合、生物酶和近红外光等条件刺激下, 多重弱键相互作用消除、动态共价键断裂 以及纳米门控元件降解等, 实现药物控制释放. 可控组装的刺激响应MSN纳米载药系统在肿瘤等疾病靶向药物治 疗方面具有应用前景。最后对刺激响应纳米载药系统的未来发展前景作进一步展望.
\end{abstract}

关键词介孔氧化硅纳米载药系统, 纳米阀, 纳米门, 刺激响应, 控制释放

癌症(恶性肿瘤)是全球性公共健康问题，已经成 为威胁人类健康的重大疾病. 近 30 年来, 世界癌症发 病率逐年升高, 我国癌症发病也呈现出年轻化、发病 率和死亡率走高的趋势, 有效医治癌症已成为当务 之急. 目前临床治疗癌症的主要手段是手术切除和 放射治疗及化学药物治疗 (以下简称放化疗), 但放化 疗对人体正常细胞也造成了严重损伤. 化疗会导致 严重的毒副作用, 产生抗药性, 治疗效率低. 理想的 药物治疗方式应该是在需要的时刻, 将所需剂量的 药物释放到人体所需要的部位, 即定时、定量、定点 给药, 才能充分利用药物的疗效, 同时降低药物的毒 副作用. 刺激响应纳米载药系统能够在肿瘤器官、组 织和细胞的特定环境刺激下实现药物控制释放, 用 于靶向治疗, 从而有效减小药物对正常组织或细胞
的损害, 达到提高药物治疗效果和降低药物毒副作 用的目的 ${ }^{[1]}$. 对于很多实际纳米载药系统, 影响药物 疗效和细胞毒性的两个最重要条件是药物“零前释 放”(在刺激前无药物渗漏)和刺激响应控制释放 ${ }^{[2]}$. 近十年来, 人们对发展各种刺激响应纳米载药系统 的研究兴趣与日俱增 ${ }^{[3]}$.

\section{1 介孔氧化硅纳米载药系统}

传统的纳米载药系统, 例如: 高分子胶束和囊泡 等主要依靠药物简单扩散和载体降解 ${ }^{[1]}$, 难以实现药 物零前释放和刺激响应控制释放. 介孔氧化硅纳米 粒子(MSN)具有良好的生物相容性、高的比表面积、 大的孔体积、均一可调的孔径、容易表面修饰等特点, 是一种比较理想的药物载体. MSN纳米载药系统的 
刺激响应控制释放引起人们的极大兴趣, 已经成为 一个研究热点. MCM-41型MSN具有二维六角排列的 平行柱状孔道(2 3 nm)结构, 这种独特的介孔结构使 药物零前释放成为可能 ${ }^{[1]}$. MSN表面可以进行种类多 样的功能化修饰, 一些纳米粒子或大分子, 例如: 量 子点、纳米金、聚合物、树状分子、大环化合物、蛋 白、核酸等, 通过多重弱键相互作用、动态共价键和 环境响应的功能基元连接在MSN表面, 并覆盖MSN 孔道口, 将药物分子封装在纳米孔道内, 构成“纳米 门”,[4 13]. 在物理(光、热等)、化学 ( $\mathrm{pH}$ 、氧化还原等) 和生化(生物酶、疾病过表达生物分子等)刺激下, 纳 米门被打开, 实现药物控制释放. 若大环化合物与修 饰在MSN表面的 “线轴”分子通过主客体相互作用形 成轮烷或准轮烷, 将药物分子封装在纳米孔道内, 构

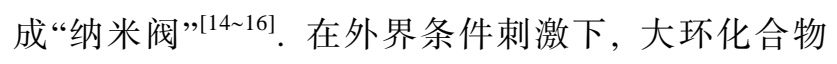
沿着MSN表面修饰的线轴分子滑动, 远离孔道口, 纳米阀被打开, 实现药物控制释放.

国内外学者在刺激响应MSN纳米载药系统的研


激响应MSN纳米载药系统的可控组装及控制释放性 能研究, 本文主要介绍我们在此领域的研究工作.

\section{1 超分子纳米阀}

葫芦腿 $(\mathrm{CB}[n])$ 是继冠醚、环糊精和杯芳烃之后 第 4 代大环主体化合物. 葫芦脲由 $n$ 个甘嫝通过 $2 n$ 个 亚甲基连接而成的结构对称的大环化合物, 具有 1 个 疏水空腔和 2 个亲水端口 ${ }^{[17]}$. 葫芦艮疏水空腔可以与 多种有机分子发生疏水作用, 而葫芦脲端口的羰基 氧原子与金属离子或正电性的有机分子发生离子-偶 极和氢键等相互作用, 形成主客体超分子体系. 在已 经报道的一系列葫芦脲中, 葫芦艮[7]的水溶性相对 较高 $(0.02 \sim 0.03 \mathrm{~mol} / \mathrm{L})^{[17]}$. 脂肪胺的氨基在中性条件 下便可发生质子化, 葫芦脲[7]与修饰在MSN表面的 (质子化的)丁二胺以较强的结合亲和性 $\left(3.7 \times 10^{5}\right.$ $\mathrm{L} / \mathrm{mol})^{[18]}$ 形成准轮烷, 构成超分子纳米阀, 将染料分 子钙黄绿素 (作为模型药物)封装在MSN孔道内, 可 控组装葫芦脲[7]阀控的丁二胺功能化的MSN纳米载 药系统 ${ }^{[19]}$. 在碱性条件下, 质子化的丁二胺去质子 化, 葫芦脲 [7] 与丁二胺的离子-偶极作用消除, 导致 葫芦脲 [7]脱离MSN表面修饰的丁二胺线轴, 纳米阀 被打开, 实现 $\mathrm{pH}$ 响应的药物控制释放 ${ }^{[19]}$. 碱性条件 引发的药物控制释放, 尽管可以用于碱性环境的组
织和器官部位的疾病治疗, 但难以在肿瘤细胞的弱 酸性环境条件下实现. 在中性条件下引人竞争结合 剂, 加人(质子化的)己二胺等化合物, 通过竞争结合 葫芦艮 [7](结合常数 $8.97 \times 10^{7} \mathrm{~L} / \mathrm{mol}$ ), 打开超分子纳 米阀, 实现药物控制释放 ${ }^{[19]}$, 满足不同条件的药物 控制释放需求. 生物体内的多胺物质是由氨基酸在 脱羧酶作用下自然生成的有机阳离子, 生物多胺合 成的增加与细胞生长和肿瘤紧密相关 ${ }^{[20]}$. 在皮肤和 结肠等上皮组织的肿瘤中, 脱羧酶和多胺的含量增 多 ${ }^{[21]}$. 将超顺磁性 $\mathrm{Fe}_{3} \mathrm{O}_{4}$ 纳米粒子嵌入 $\mathrm{MSN}$, 作为药 物载体, 可控组装葫芦艮 [7]阀控的丁二胺功能化的 磁性MSN纳米载药系统 ${ }^{[22]}$. 赖氨酸与葫芦艮 [7]的结 合亲和性 $(870 \mathrm{~L} / \mathrm{mol})^{[18]}$ 较弱, 不足以打开超分子纳 米阀. 赖氨酸在脱羧酶的作用下生成戊二胺, 质子化 的戊二胺能够竞争结合葫芦艮 [7](结合常数 $1.4 \times 10^{7}$ $\mathrm{L} / \mathrm{mol})^{[18]}$, 本课题组 ${ }^{[22]}$ 首次报道生物酶引发的葫芦 脲超分子纳米阀的控制释放. 释放的分子不但可以 是探针分子, 用于检测氨基酸脱羧酶和生物多胺的 含量, 还可以是有效药物, 调控细胞的多胺合成和用 于肿瘤治疗, 在生物传感和体内靶向给药方面具有 应用前景.

2008年, Ogoshi等人 ${ }^{[23]}$ 首次报道一种通过对二酚 醚和亚甲基连接而成的结构对称的柱型大环化合 物一一柱芳烃. 随后，一些极性基团取代的水溶性柱 芳烃也相继报道. 2010 和 2012 年分别报道羒基化 柱[5]芳烃和柱[6]芳烃 ${ }^{[24,25]}$. 柱芳烃的主客体化学及 相关应用研究引起人们的兴趣 ${ }^{[16,26]}$. 针对水溶性羧 基化柱 [6]芳烃(CPA[6]), 本课题组 ${ }^{[27]}$ 设计合成一个 新型客体分子一一苯并咪唑类阳离子, 通过静电作 用、 $\pi-\pi$ 作用和疏水作用等，与CPA[6]形成高亲和性 的 $1: 1$ 计量比的包合物, 结合常数为 $(2.82 \pm 1.83) \times 10^{5}$ $\mathrm{L} / \mathrm{mol}$. 甲基紫晶(二甲基联吡啶阳离子, MV)带有 2 个 正电荷, 能够与 CPA[6]形成 $1: 1$ 计量比的包合物, 结 合常数高达 $(1.02 \pm 0.10) \times 10^{8} \mathrm{~L} / \mathrm{mol}^{[25]}$. 分别将苯并咪 唑阳离子或联吡啶阳离子修饰在 MSN表面, 与 CPA[6]形成准轮烷, 构成超分子纳米阀, 将染料分 子联吡啶钉配合物或抗肿瘤药物阿需素封装在MSN 纳米孔道内, 可控组装 $\mathrm{CPA}$ [6]阀控的苯并咪唑阳 离子或联吡啶阳离子功能化的 MSN纳米载药系统 (图 1) ${ }^{[27]}$. 在酸性条件下, CPA[6]的羧酸根发生质子 化形成羧基，导致 CPA[6]的负电荷减少和溶解性降 低, 削弱 CPA[6]与修饰在MSN表面的苯并咪唑阳离 


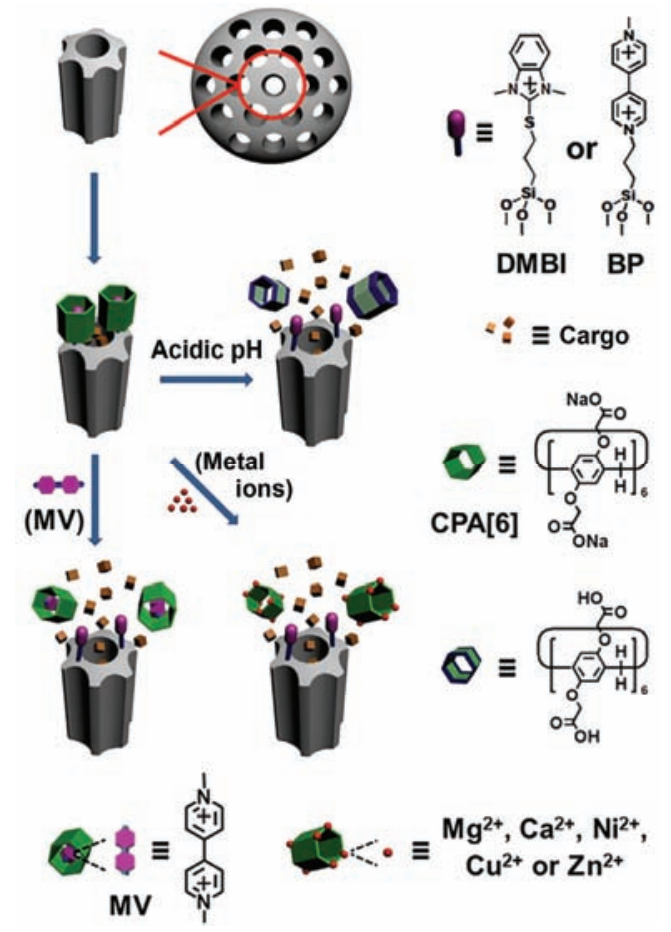

图 1 (网络版彩色)CPA[6]阀控的苯并咪唑阳离子或联吡啶阳离子 功能化的 $\mathrm{MSN}$ 纳米载药系统的可控组装及 $\mathrm{pH}$ 、金属配位和竞争结合 多重刺激响应控制释放 ${ }^{[27]}$

Figure 1 (Color online) Construction of CPA[6]-valved MSN drug delivery systems functionalized with dimethylbenzimidazolium (DMBI) or bipyridinium (BP) stalks for multi-responsive controlled release triggered by acidic $\mathrm{pH}$, metal chelating, and competitive binding ${ }^{[27]}$

子或联吡啶阳离子的静电相互作用, 使 CPA[6]脱离 苯并咪唑阳离子或联吡啶阳离子线轴, 超分子纳米 阀被打开, 实现 $\mathrm{pH}$ 响应的药物控制释放 ${ }^{[27]}$. 许多肿 瘤或炎症组织呈现弱酸性环境, 因此 $\mathrm{pH}$ 响应的纳米 载药系统在肿瘤治疗方面有着潜在的应用前景. $\mathrm{CPA}[6]$ 的羧酸根能够与金属离子 $\left(\mathrm{Cu}^{\mathrm{II}}, \mathrm{Zn}^{\mathrm{II}}, \mathrm{Ni}^{\mathrm{II}}, \mathrm{Ca}^{\mathrm{II}}\right.$ 和 $\mathrm{Mg}^{\mathrm{II}}$ ) 发生配位作用, 导致 $\mathrm{CPA}[6]$ 的负电荷减少, $\mathrm{CPA}[6]$ 与苯并咪唑阳离子或联吡啶阳离子的结合亲 和性降低, 超分子纳米阀被打开, 实现金属配位刺激 响应的药物控制释放 ${ }^{[27]}$. 这是首次利用配位化学策 略激活柱芳烃超分子纳米阀实现药物控制释放. 除 了 $\mathrm{Cu}^{\mathrm{II}}$, 金属配位引起的药物释放效率与金属离子与 羧酸盐的 $1: 1$ 配合物的结合亲和性一致. $\mathrm{Cu}^{\mathrm{II}}$ 引起的 异常释放行为与中性溶液中 $\mathrm{Cu}^{\mathrm{II}}$ 的分配系数和不同 $\mathrm{Cu}^{\mathrm{II}}$ 物种配位平衡相关. 此外, 加人甲基紫晶竞争结 合剂, CPA[6]超分子纳米阀被打开, 实现药物释放控 制 ${ }^{[27]}$. 可控组装的两种 CPA[6]阀控的MSN纳米载药 系统均可实现 $\mathrm{pH}$ 、金属配位和竞争结合多重刺激响
应的药物控制释放. 在不装载药物的情况下, CPA[6] 阀控的苯并咪唑阳离子功能化的 MSN与 A549细胞 (人肺腺癌细胞)孵化 $48 \mathrm{~h}$ 后显示低的细胞毒性, 而装 载阿霉素的纳米载药系统将肿瘤细胞的存活率降低 至 $20 \%{ }^{[27]}$, 这主要是由于细胞内弱酸环境引起的药 物释放, 该 CPA[6]阀控的MSN纳米载药系统在肿瘤 药物治疗方面具有潜在的应用前景.

\section{2 环糊精纳米门}

环糊精 $(\mathrm{CD})$ 含有 $6 \sim 8$ 个 D-吡喃葡萄糖单元, 通过 $\alpha-1,4$-糖苷键连接形成大环, $\mathrm{O} 2$ 和 $\mathrm{O} 3$ 位仲羟基位于大 环的宽口一端, 而O6位伯羟基位于大环的窄口一端, 形成了中空的截顶圆雉形状. 具有亲水表面和憎水 空腔的环糊精能够容纳憎水性药物. 类似上述的葫 芦艮和柱芳烃超分子纳米阀, 基于环糊精的主客体 化学, 文献中已有很多环糊精阀控的MSN纳米载药 系统的报道 ${ }^{[28,29]}$. 本课题组 ${ }^{[30]}$ 提出一个全新的设计 理念, 充分利用环糊精的独特结构和性质, 通过动态 共价键将环糊精连接在MSN表面, 环糊精不仅作为 门控元件, 而且作为药物载体.

苯硼酸 (PBA)及其衍生物是一种Lewis酸, 能够 与 1,2 二醇和 1,3 二醇 $($ 糖类化合物和其他含二醇的化 合物)形成喼酸酯, 结合亲和性与各自的 $\mathrm{p} K_{\mathrm{a}}$ 和溶液 $\mathrm{pH}$ 有关。喼酸酯通常在碱性条件下形成，而在中性 和弱酸性条件下发生水解 ${ }^{[31,32]}$. 通过两种方法可以 降低苯硼酸的 $\mathrm{p} K_{\mathrm{a}}$, 以便在生理 $\mathrm{pH}$ 条件下形成稳定的 硼酸酯. 一种方法是在硼酸基团的间位引人吸电子 基团, 另一种方法是在苯磀酸基团附近引人氨基, 通 过 $\mathrm{N}-\mathrm{B}$ 配位作用降低苯嗍酸的表观 $\mathrm{p} K_{\mathrm{a}}{ }^{[33,34]}$. 只是在 硼酸基团的间位引人氨甲酰基，不足以使苯硼酸与 $\gamma$-CD有效共价结合 ${ }^{[30]}$. 在MSN表面同时修饰二硫键 连接的氨甲酰基苯嗍酸和脂肪胺，在苯硼酸基团附 近引人氨基, 可以促进硼酸与氨基之间的Lewis酸/碱 相互作用, 邻近氨基的离子对稳定效应和 $\mathrm{N}-\mathrm{B}$ 配位 作用，明显降低了苯嗍酸的表观 $\mathrm{p} K_{\mathrm{a}}^{[30]}$. 通过分子间 $\mathrm{N}-\mathrm{B}$ 配位作用, $\gamma$-CD的仲羟基与苯硼酸能够在中性 $\mathrm{pH}$ 条件下形成稳定的嗍酸酯键, $\gamma-\mathrm{CD}$ 通过动态共价 键结合到 MSN表面, 构成 $\gamma-\mathrm{CD}$ 纳米门, 将染料分子 (罗丹明 $6 \mathrm{G}$ 或钙黄绿素)封装于MSN孔道中 ${ }^{[30]}$. 然后, 另外一种抗肿瘤药物(喜树碱或阿霉素)通过主客体 包结作用进人 $\gamma-C D$ 空腔中 ${ }^{[30]}$. MSN表面紧密包裹的 $\gamma-\mathrm{CD}$ 起到了生物模拟富含糖类的细胞表面的作用 ${ }^{[35]}$, 
增强MSN纳米载药系统在血清中的稳定性. 基于双 重动态共价键 (二硫键和硼酸酯键) 和主客体相互作 用, 可控组装环糊精门控的苯嗍酸功能化的MSN纳 米双载药系统, 能够实现双载药的同时和连续控制 释放(图2) ${ }^{[30]}$.

在酸性条件, 嗍酸酯键被水解, 同时 $\gamma-\mathrm{CD}$ 空腔 包结的药物分子被质子化, 降低二者结合亲和性, 两 种药物分别从 MSN孔道和 $\gamma-\mathrm{CD}$ 空腔中同时释放出


的同时控制释放. 在 $\mathrm{pH}$ 7.4条件下, 加人果糖或半乳 糖 $(0.01 \mathrm{~mol} / \mathrm{L})$ 竞争结合苯嗍酸, 明显观察到罗丹明 $6 \mathrm{G}$ 的释放, 而未观察到喜树碱的释放 ${ }^{[30]}$. 然而, 加 人葡萄糖 $(0.01 \mathrm{~mol} / \mathrm{L})$, 既不能引发罗丹明 $6 \mathrm{G}$ 的释放,
也不能使喜树碱释放 ${ }^{[30]}$. 果糖或者半乳糖与 $\gamma-\mathrm{CD}$ 竞 争结合苯硣酸, 通过动态嗍酸酯键的断裂和重新形

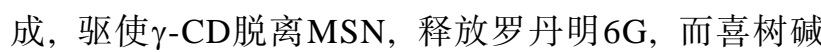
仍然包结在 $\gamma-C D$ 空腔中 ${ }^{[30]}$. 因此, 在生理条件下正 常血糖浓度不能引发 $\gamma-\mathrm{CD} 门$ 控的MSN纳米双载药系 统的药物的前释放. 进一步降低至 $\mathrm{pH}$ 5.0, 可以观察 到喜树碱从 $\gamma-\mathrm{CD}$ 空腔中释放出来 ${ }^{[30]}$. 显然, 首先通 过果糖或者半乳糖竞争结合, 然后将溶液调节至弱 酸性, 能够实现 $\gamma-\mathrm{CD} 门$ 控的MSN纳米双载药系统的 药物连续控制释放 ${ }^{[30]}$. 可是, 在生理条件下, 果糖和 半乳糖的浓度几乎比葡萄糖的浓度低 2 个数量级. 类 似地, 在还原剂二硫苏糖醇(DTT)或者谷胱甘肽 $(\mathrm{GSH})$ 存在下, 断裂二硫键, 装载在MSN孔道中的钙
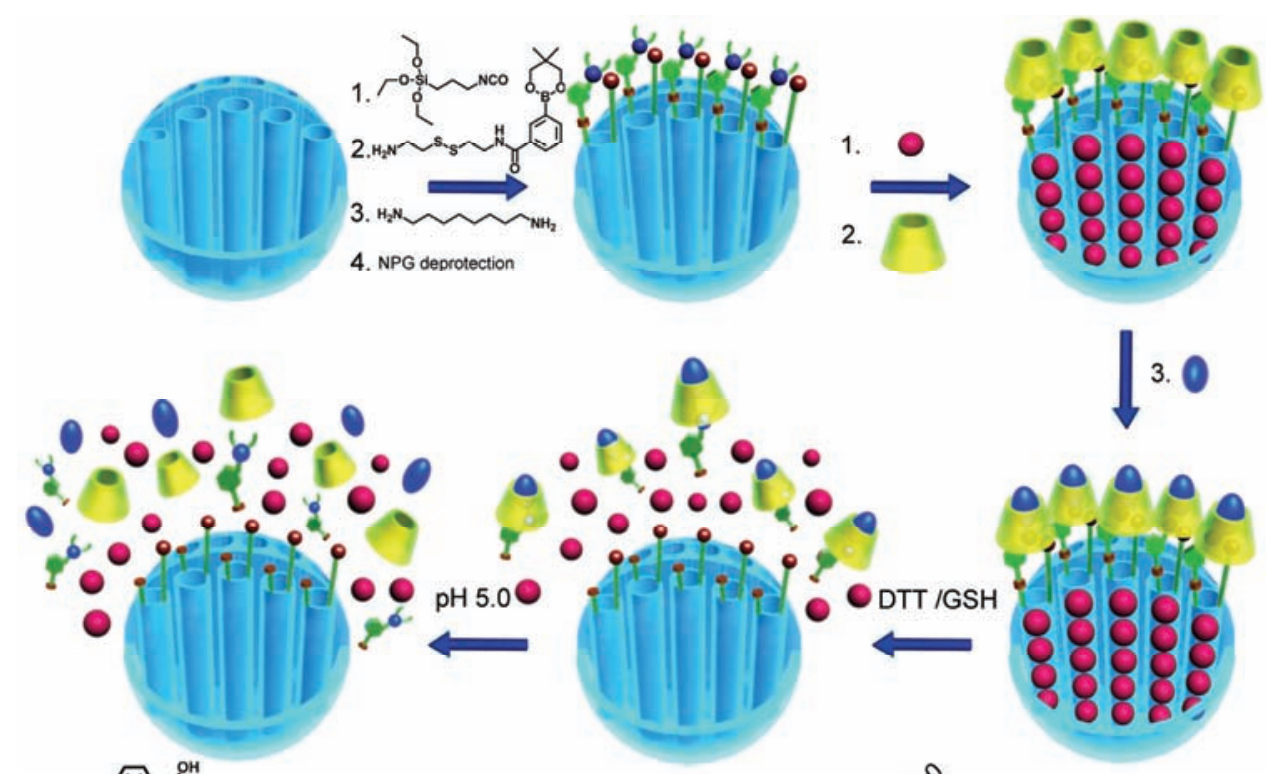

3.
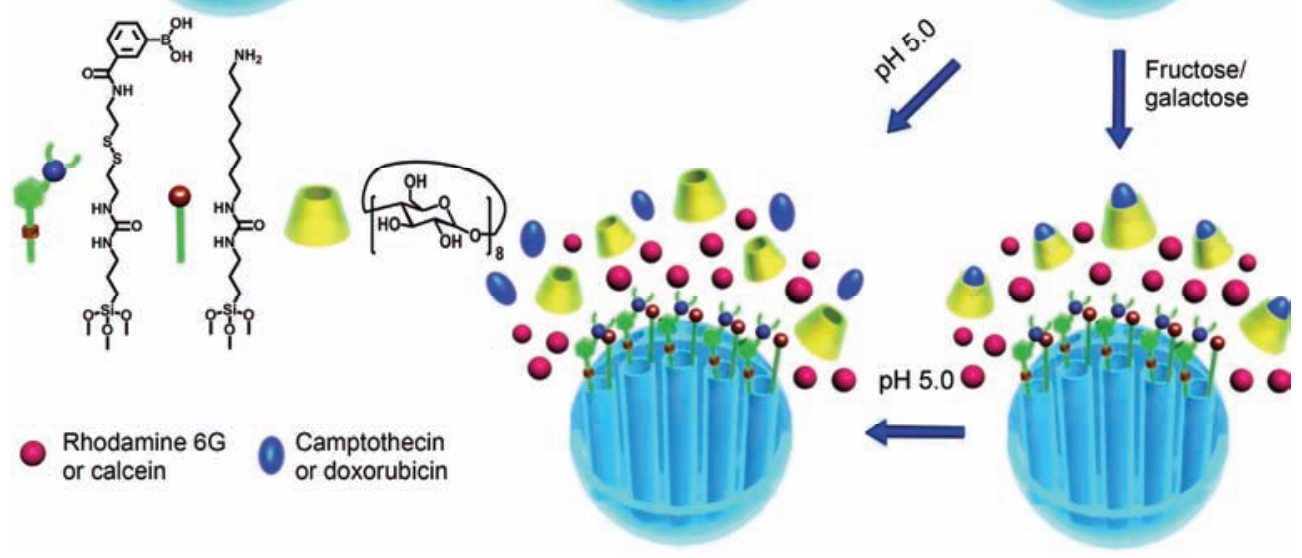

图 2 (网络版彩色) $\gamma-\mathrm{CD} 门$ 门空的二硫键连接的氨甲酰基苯硼酸功能化的MSN纳米双载药系统的可控组装及封装在MSN孔道和 $\gamma-\mathrm{CD}$ 空腔的两种 药物的同时和连续控制释放 ${ }^{[30]}$

Figure 2 (Color online) Construction of $\gamma$-CD-gated MSN drug delivery systems functionalized with disulfide-linked carbamoylphenylboronic acids and amines for simultaneous and cascade release of two drugs entrapped in the MSN pores and included inside the $\gamma$-CD cavities ${ }^{[30]}$ 
黄绿素首先被释放出来, 通过降低 $\mathrm{pH}$, 另一种药物 阿霉素也从 $\gamma-\mathrm{CD}$ 空腔中释放出来 ${ }^{[30]}$. 肿瘤组织通常 表现为弱酸性环境和含有高表达的 GSH, 两种药物 的同时和连续控制释放可以使治疗效果最大化, 有 助于克服抗药性. 将喜树碱和阿需素分别装载于 $\mathrm{MSN}$ 孔道和 $\gamma-\mathrm{CD}$ 空腔中, $\gamma-\mathrm{CD}$ 门控的双重动态共价 键连接的苯嗍酸功能化的MSN纳米双载药系统分别 与 A549细胞和 HeLa细胞 (人宫颈癌细胞) 孵化 $24 \mathrm{~h}$. A549细胞除了肿瘤细胞具有的弱酸性环境外, GSH 含量较高. A549细胞的弱酸性环境和高表达的 GSH 引起两种药物同时/连续控制释放以及两种药物的协 同作用, A549细胞比HeLa细胞显示更低的存活率, 证实联合药物治疗能够明显提高治疗效果. 通过激 光共聚焦显微镜进一步观察两种药物在细胞内的释 放行为 ${ }^{[30]}$. 可控组装的 $\gamma-\mathrm{CD}$ 门控的双重动态共价键 连接的苯嗍酸功能化的MSN纳米双载药系统可以抵 御血清和正常血糖生理环境, 在肿瘤联合药物治疗 方面具有实际的应用前景.

\section{3 蛋白纳米门}

生物大分子门控的 MSN纳米载药系统的生物相 容性远优于其他类分子和无机纳米粒子门控系统 ${ }^{[12]}$, 并能对外界物理、化学和生物信号发生灵敏响应. 蛋 白与核酸是生命活动的物质基础, 是最重要的生物 大分子. 尽管蛋白种类繁多, 但是文献报道的蛋白门 控的MSN纳米载药系统的研究工作却较少. 主要通 过酶降解蛋白和断裂连接蛋白与MSN表面的二硫键, 这些研究工作与蛋白自身特有性质相关性不大. 基 于配体与蛋白受体相互作用的这一策略, 能够可控 组装蛋白门控的MSN纳米载药系统. 生物素与亲和 素的作用力是自然界存在的最强的非共价相互作用, 结合常数高达 $10^{13} \sim 10^{15} \mathrm{~L} / \mathrm{mol}$. 由于生物素与亲和素 结合亲和性太强, 由此构筑的亲和素门控的MSN纳 米载药系统难以在温和条件下发生刺激响应药物释 放 ${ }^{[36]}$.

糖与蛋白的单重位点相互作用一般较弱, 结合 常数只有 $10^{3} \sim 10^{4} \mathrm{~L} / \mathrm{mol}^{[37]}$, 难以构成有效的蛋白纳 米门, 而糖与蛋白的多重位点相互作用的结合常数 则能够达到 $10^{6} \sim 10^{7} \mathrm{~L} / \mathrm{mol}^{\text {甚至更高 }}{ }^{[37]}$, 适合构成有 效的蛋白纳米门, 同时又能在温和刺激条件下打开 纳米门. 伴刀豆球蛋白 (Con A) 在中性 $\mathrm{pH}$ 条件下以四 聚体形式存在, 在 $\mathrm{Ca}^{\mathrm{II}}$ 和 $\mathrm{Mn}^{\mathrm{II}}$ 存在下能够与甘露糖或
者葡萄糖发生特异性结合, 但是Con $\mathrm{A}$ 与甘露糖的亲 和性更强 ${ }^{[38]}$. 设计合成不同长度的寡聚乙二醇间链 连接的含甘露糖配体的硫醇分子, 与烯丙基三乙氧 基硅烷通过統基-烯“点击”化学反应形成含甘露糖配 体的硅烷, 将其修饰在MSN表面 ${ }^{[39]}$. 在 $\mathrm{Ca}^{\mathrm{II}}$ 和 $\mathrm{Mn}^{\mathrm{II}}$ 存 在条件下, 糖配体进入蛋白结合口袋发生糖与蛋白 特异性结合. 低表面密度的糖配体不利于与蛋白发 生多重位点相互作用, 而高表面密度的糖配体由于 相邻配体之间的空间拥挤效应也不利于蛋白多重位 点结合, 蛋白特异性结合量与糖配体的表面密度和 空间分布紧密相关, 并受控于这两种因素的相互制 约 ${ }^{[40 \sim 43]}$. 寡聚乙二醇柔性间链能够较好地局部调整 MSN表面的甘露糖配体的空间分布, 有利于蛋白多 重作用位点结合, 将药物的前释放尽可能降低 ${ }^{[39]}$. 可见, MSN表面的蛋白特异性结合量与甘露糖配体 的表面密度和空间分布有关. 基于糖与 Con A多重相 互作用, 可控组装Con A门控的甘露糖功能化的MSN 纳米载药系统(图3), 将罗丹明 6G封装于 MSN孔道 中 $^{[38]}$. 在酸性条件下, 参与蛋白结合的 $\mathrm{Ca}^{\mathrm{II}}$ 和 $\mathrm{Mn}^{\mathrm{II}}$ 会 游离出来, 导致Con A从甘露糖功能化的 MSN表面脱 离, 与此同时, 在 $\mathrm{pH}$ 小于 5.5 , Con A四聚体会解聚成 二聚体或者单体, 这两种因素均导致蛋白纳米门被 打开, 罗丹明 $6 \mathrm{G}$ 被释放出来 ${ }^{[39]}$. 在 $\mathrm{Ca}^{\mathrm{II}}$ 和 $\mathrm{Mn}^{\mathrm{II}}$ 存在下, 葡萄糖也能与Con A发生特异性结合, 但结合亲和性 弱于甘露糖. 在正常血糖浓度范围内, 葡萄糖不能引 起明显药物释放, 随着葡萄糖浓度增加, 葡萄糖与 Con A发生竞争结合, 驱使蛋白离开MSN表面, 导致 药物释放 ${ }^{[39]}$. 显然, 可控组装的蛋白门控的 MSN纳 米载药系统在肿瘤和糖尿病的药物治疗方面具有潜 在的应用前景.

此外，基于配体-金属-蛋白的金属桥联配位作 用, 能够可控组装蛋白门控的MSN纳米载药系统. 在 $\mathrm{Cu}^{\mathrm{II}}$ 或 $\mathrm{Ni}^{\mathrm{II}}$ 存在下, 亚胺二乙酸(IDA)或次氨三乙酸 (NTA)功能化表面通过金属配位结合表面富含组氨 酸残基的蛋白或组氨酸标记蛋白, 常用于蛋白固载 和分离提纯. IDA与 $\mathrm{Cu}^{\mathrm{II}}$ 结合常数高达 $10^{10} \mathrm{~L} / \mathrm{mol}$, 形 成的IDA-Cu ${ }^{\mathrm{II}}$ 配合物可与 1 个组氨酸残基发生配位作 用(结合常数 $\left.10^{3.5} \mathrm{~L} / \mathrm{mol}\right)$, 也能与含有 2 个表面组氨酸 残基的蛋白发生多重位点结合作用，表观结合常数 大于 $10^{6} \mathrm{~L} / \mathrm{mol}^{[44]}$. 肌红蛋白含有 11 个组氨酸残基, 其中 5 个组氨酸残基暴露在外表面, 可与 IDA- $\mathrm{Cu}^{\mathrm{II}}$ 配 合物发生多重位点的配位作用 ${ }^{[45,46]}$. 将 $N$ - (三甲氧基 


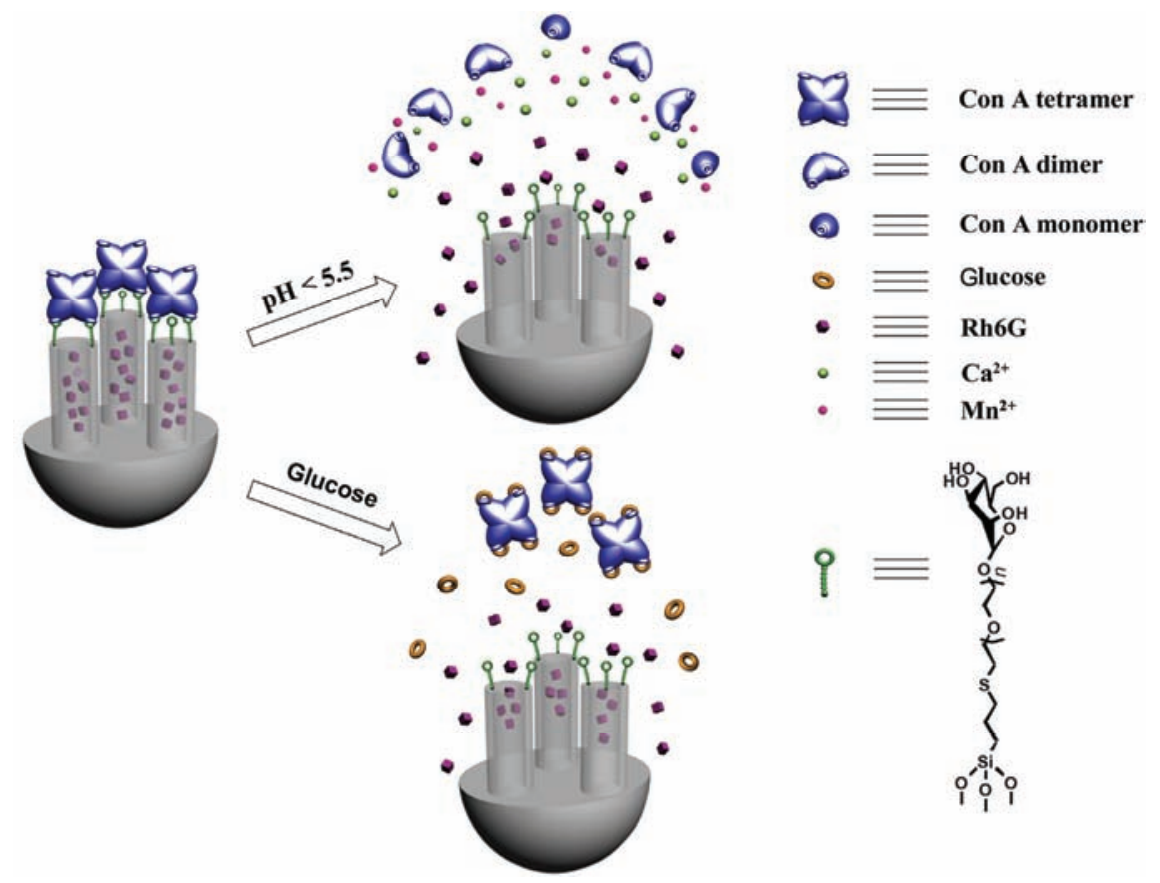

图 3 (网络版彩色)Con A门控甘露糖功能化的MSN纳米载药系统的可控组装及pH响应和葡萄糖竞争结合引发的药物控制释放 ${ }^{[39]}$

Figure 3 (Color online) Controlled release of cargo from Con A-gated MSN delivery systems functionalized with mannose moieties in response to changes in $\mathrm{pH}$ value and glucose concentration ${ }^{[39]}$

硅丙基)乙二胺三乙酸修饰在MSN表面, 乙二胺三乙 酸(DATA) 是一个五齿配体, 含有 1 个IDA或类似于 NTA的结构单元. 过渡金属离子可以与DATA功能化 的MSN形成 $1: 1$ 或 $1: 2$ 的DATA-金属配合物 ${ }^{[47]}$. 处于 MSN孔道口附近的 2 个DATA配体可以同时与 1 个金 属离子配位结合, 形成类似于以金属离子为“门”的 门控结构 ${ }^{[47]}$, 从而将染料分子联吡啶钉配合物封装 于MSN纳米孔道中. 肌红蛋白表面的组氨酸残基能 够与MSN表面的DATA-金属配合物的配位不饱和位 点发生配位作用. 肌红蛋白以多重位点的配位作用 牢固地结合到DATA功能化的MSN表面, 结合的蛋 白将单独金属配位未能封堵的MSN孔道口覆盖, 从 而提高药物的装载量和释放效率 ${ }^{[47]}$. 基于配体-金属肌红蛋白表面组氨酸残基的金属桥联配位作用, 可 控组装金属配位与肌红蛋白金属配位协同门控的 DATA功能化的 MSN纳米载药系统 (图4) ${ }^{[47]}$. 金属离 子与配体的结合强度受溶液 $\mathrm{pH}$ 影响, 通过调控 $\mathrm{pH}$ 实 现蛋白金属配位门控的纳米载药系统的药物控制释 放. 随着DATA配体表面密度增加, 配体-金属离子 门门控的纳米载药系统的 $\mathrm{pH}$ 响应的药物释放效率逐 渐提高 ${ }^{[47]}$. 在金属离子与蛋白同时存在条件下组装 的纳米载药系统比单独金属配位组装的纳米载药系
统具有更高的药物释放效率，但释放效率几乎与 DATA表面密度无关 ${ }^{[47]}$. 配体-金属离子门的形成与 蛋白多重配位结合作用同时发生，通过二者的协同 门控作用能够有效提高药物的装载量和释放效率 ${ }^{[47]}$. 在不载药情况下, 金属配位与肌红蛋白金属配位协 同门控的DATA功能化的MSN与A549细胞孵化 $48 \mathrm{~h}$ 后显示较低的细胞毒性, 而装载阿霉素的纳米载药 系统将肿瘤细胞的存活率降低至不足 $20 \%{ }^{[47]}$, 该 纳米载药系统在肿瘤药物治疗方面具有潜在的应用 前景.

\subsection{DNA纳米门}

存在于细胞核中的DNA是很多药物作用的靶标, 药物分子和双链DNA之间存在 3 种非共价结合方式: 静电结合、沟槽结合和嵌插结合. 嵌插结合是一些抗 菌和抗肿瘤药物分子与双链DNA作用的主要机制. 无需设计特定的基因序列/塞聚核苷酸用于互补杂化, 也无需设计特定功能响应基团用于打开纳米门，本 课题组 ${ }^{[48]}$ 以天然DNA作为门控元件, 同时DNA又作 为药物载体, 首先在MSN表面修饰3-异氭酸丙基三 乙氧基硅烷, 然后与氨基端基的二硫键连接的叭啶 胺衍生物反应, 功能化修饰MSN表面 ${ }^{[48]}$. 天然双链 


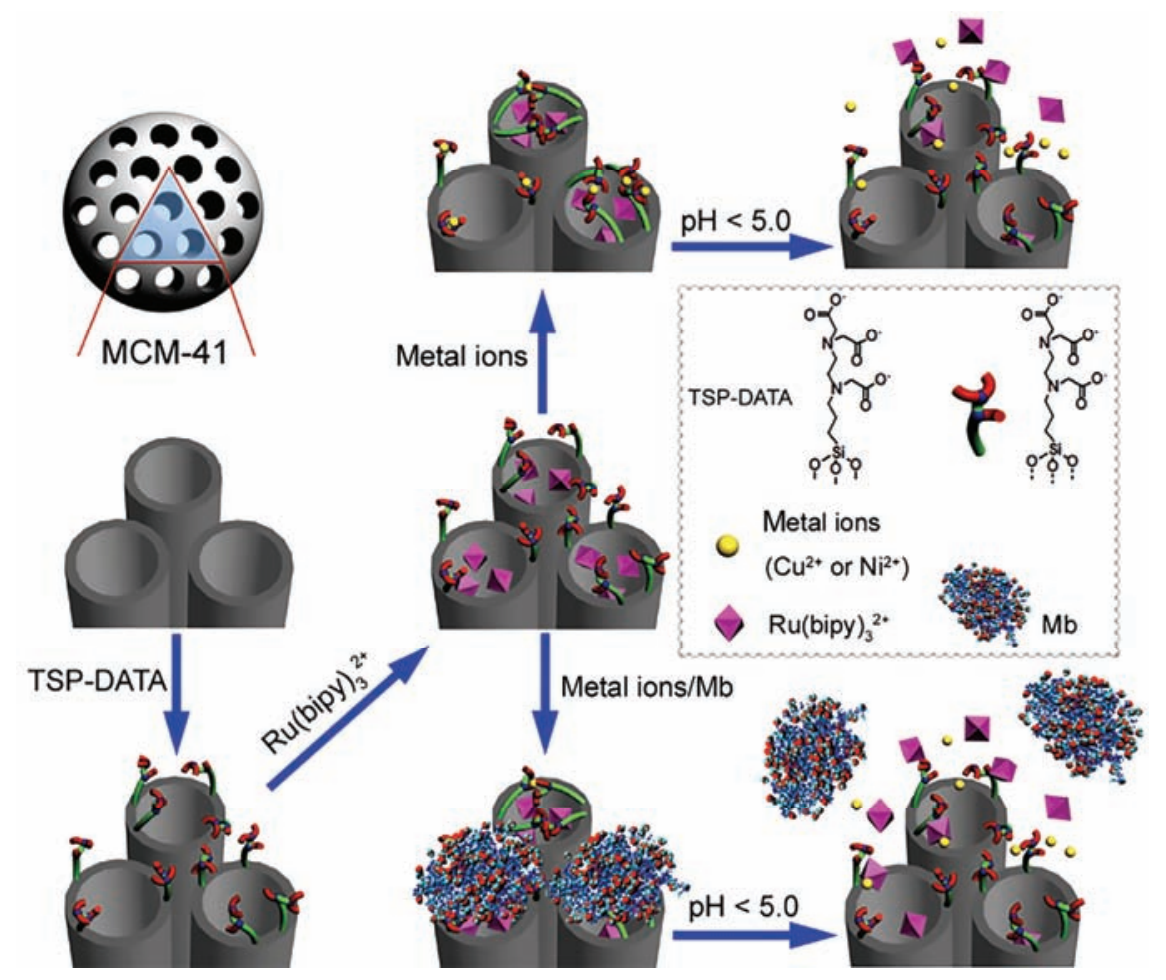

图 4 (网络版彩色)金属配位与肌红蛋白金属配位协同门控的DATA五齿配体功能化的MSN纳米载药系统的可控组装及pH响应的药物控制释放 ${ }^{[47]}$ Figure 4 (Color online) Synergistic gating of metal latching and metal-chelating myoglobin for MSN drug delivery systems functionalized with pentadentate ligands of DATA and $\mathrm{pH}$-responsive controlled release ${ }^{[47]}$

DNA(小牛胸腺DNA)通过嵌插作用结合在呋啶胺功 能化的MSN表面, 将钻黄绿素封装于纳米孔道内, 可控组装DNA门控的二硫键连接的呋啶胺功能化的 MSN纳米载药系统(图5) ${ }^{[48]}$.

DNA门控的纳米载药系统能够实现多重刺激响 应的药物控制释放 ${ }^{[48]}$. 加人二硫键还原剂 (GSH或 DTT), 断裂二硫键, 嵌插有呋啶胺的双链DNA脱离 MSN表面, 导致钻黄绿素从MSN孔道中释放出来. 升高温度, 双链DNA发生热至变性, 去杂化成为单 链DNA, DNA纳米门被打开, 钙黄绿素被释放出来. 加人脱氧核糖核酸酶(DNase I), 双链DNA被水解成 寡聚核苷酸, 纳米门被打开, 钙黄绿素被释放出来. 在多重刺激响应的钻黄绿素释放过程中, DNA门控 元件以不同形式从MSN表面脱离进人周围溶液环境, 同时达到DNA/基因传递的目的. 结合两种刺激方式 (二硫键还原/DNase I或二硫键还原/升高温度), 进一 步实现呋啶胺衍生物的控制释放. 该纳米载药系统 实现了“AND”逻辑门控制释放, 有望在复杂的生理 环境下实现药物释放的精确控制. 尽管升高温度难 以直接实际应用, 通过将近红外光热转换元件引人
MSN载体, 能够实现光热引起药物释放的目的. 可 控组装的DNA门控的呋啶胺功能化的MSN纳米载药 系统，集多重刺激响应和“AND”逻辑门控于单个智 能纳米器件为一体, 不仅实现药物和DNA/基因的共 传递, 而且实现两种药物的连续控制释放, 这种多功 能纳米载药系统可以用于联合药物治疗, 克服抗药 性, 显著提高药物治疗效果.

磷酸/膦酸与金属离子 $\left(\mathrm{Fe}^{\mathrm{III}}, \mathrm{Zr}^{\mathrm{IV}}\right.$ 和 $\mathrm{Ti}^{\mathrm{IV}}$ 等 $)$ 之间存 在很高的结合亲和性 ${ }^{[49]}$. 本课题组 ${ }^{[50]}$ 首次利用DNA 配位化学策略, 基于膦酸基团 $-\mathrm{Ti}^{\mathrm{IV}}$-DNA磷酸基团的 配位作用, 在MSN表面修饰环氧基团再氨基化, 然 后连接膦酸基团再 $\mathrm{Ti}^{\mathrm{IV}}$ 配位, 与天然 $\mathrm{DNA}$ (鲑鱼精 DNA)的磷酸基团形成多重配位作用，增强DNA特异 性结合和结合亲和性, 双链DNA配位结合在MSN表 面, 构成DNA纳米门, 将钻黄绿素封装于纳米孔道 中, DNA门控元件同时还能作为药物载体, 将听啶胺 嵌插结合在DNA门控元件中, 可控组装DNA门控的 $\mathrm{Ti}^{\mathrm{IV}}$ 配位膦酸功能化的 MSN纳米双载药系统(图6). 在DNase I存在下, 双链DNA被水解为寡聚核苷酸, 导致钙黄绿素和呋啶胺同时控制释放. 升高温度, 双 


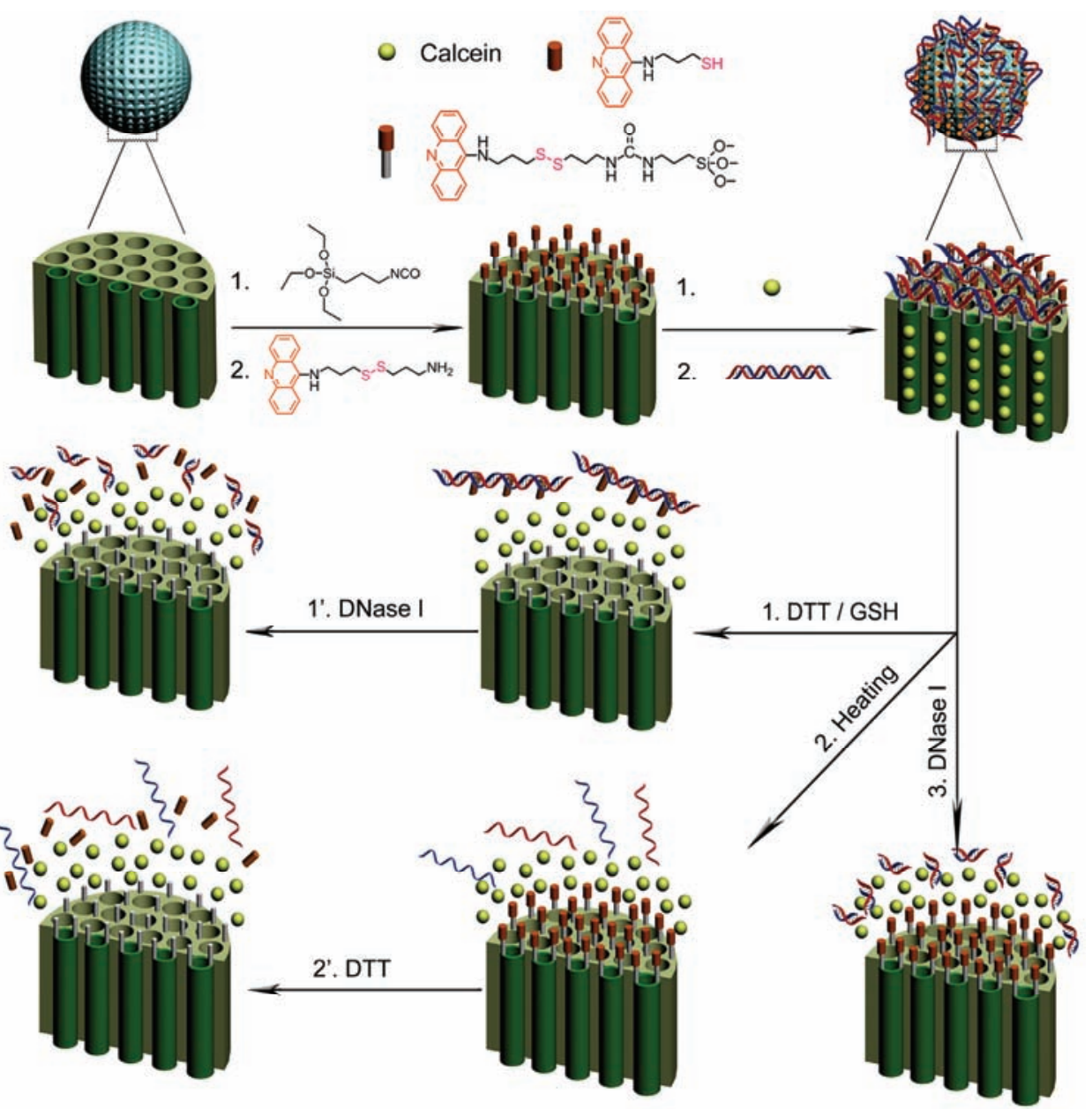

图 5 (网络版彩色)DNA门控的二硫键连接的呋啶胺功能化的MSN纳米载药系统的可控组装及封装在MSN纳米孔道的钙黄绿素的多重响应控 制释放和呋啶胺的逻辑门控释放 ${ }^{[48]}$

Figure 5 (Color online) Construction of DNA-gated MSN drug delivery systems functionalized with disulfide-linked acridinamine intercalators and for multi-responsive controlled release of calcein encapsulated in the MSN pores and logic controlled release of acridinamine ${ }^{[48]}$

链DNA发生热至变性, 去杂化成为单链DNA, 也能 实现两种药物的同时控制释放 ${ }^{[50]}$. 在碱性条件下, 参与桥联配位的 $\mathrm{Ti}^{\mathrm{IV}}$ 形成不溶性的 $\mathrm{Ti}^{\mathrm{iV}}$ 氢氧水合物种, 脱离MSN表面，导致DNA纳米门被打开，但只有钙 黄绿素释放出来, 随后升高温度, 叮啶胺相继释放出 来, 实现双载药的连续控制释放 ${ }^{[50]}$. 不载药的 DNA 门控的 $\mathrm{Ti}^{\mathrm{IV}}$ 配位膦酸功能化的 MSN与 HepG2细胞 (人 肝癌细胞)孵化 $24 \mathrm{~h}$ 后显示较低的细胞毒性. 将喜树 碱和阿需素分别装载于 MSN 孔道和双链DNA 中, DNA门控的 $\mathrm{Ti}^{\mathrm{IV}}$ 配位膦酸功能化的 MSN纳米双载药 系统将肿瘤细胞的存活率降低至 $25 \%$ 左右, 这主要 是纳米载药系统的双链DNA门控元件被细胞内的酶 解所致. 通过激光共聚焦显微镜进一步观察到两种 药物在细胞内几乎同步发生释放 ${ }^{[50]}$.
进一步用嵌人金纳米棒的 MSN核壳纳米粒子 (GNR@MSN)代替 MSN，可控组装DNA门控的 $\mathrm{Ti}^{\mathrm{IV}}$ 配 位膦酸功能化的GNR@MSN纳米双载药系统 ${ }^{[50]}$. 近 红外光是非常有效的物理刺激方式，皮肤和生物组 织对其吸收极小, 具有无损害、组织穿透深等优点. 通过金纳米棒的近红外光热转换, 实现两种药物的 同时控制释放 ${ }^{[50]}$. 类似地, 首先在碱性条件引发再 用近红外光照刺激, 实现双载药的连续控制释放. 这 种DNA门控的 $\mathrm{Ti}^{\mathrm{IV}}$ 配位膦酸功能化的GNR@MSN纳 米双载药系统，能够实现双载药的同时和连续控制 释放 ${ }^{[50]}$. DNA门控的纳米载药系统可控组装方法简 便，具有普适性，在联合药物治疗方面具有潜在的应 用前景. 不载药的DNA门控的 $\mathrm{Ti}^{\mathrm{IV}}$ 配位膦酸功能化的 GNR@MSN与MCF-7细胞(人乳腺癌细胞)捊化 $24 \mathrm{~h}$ 


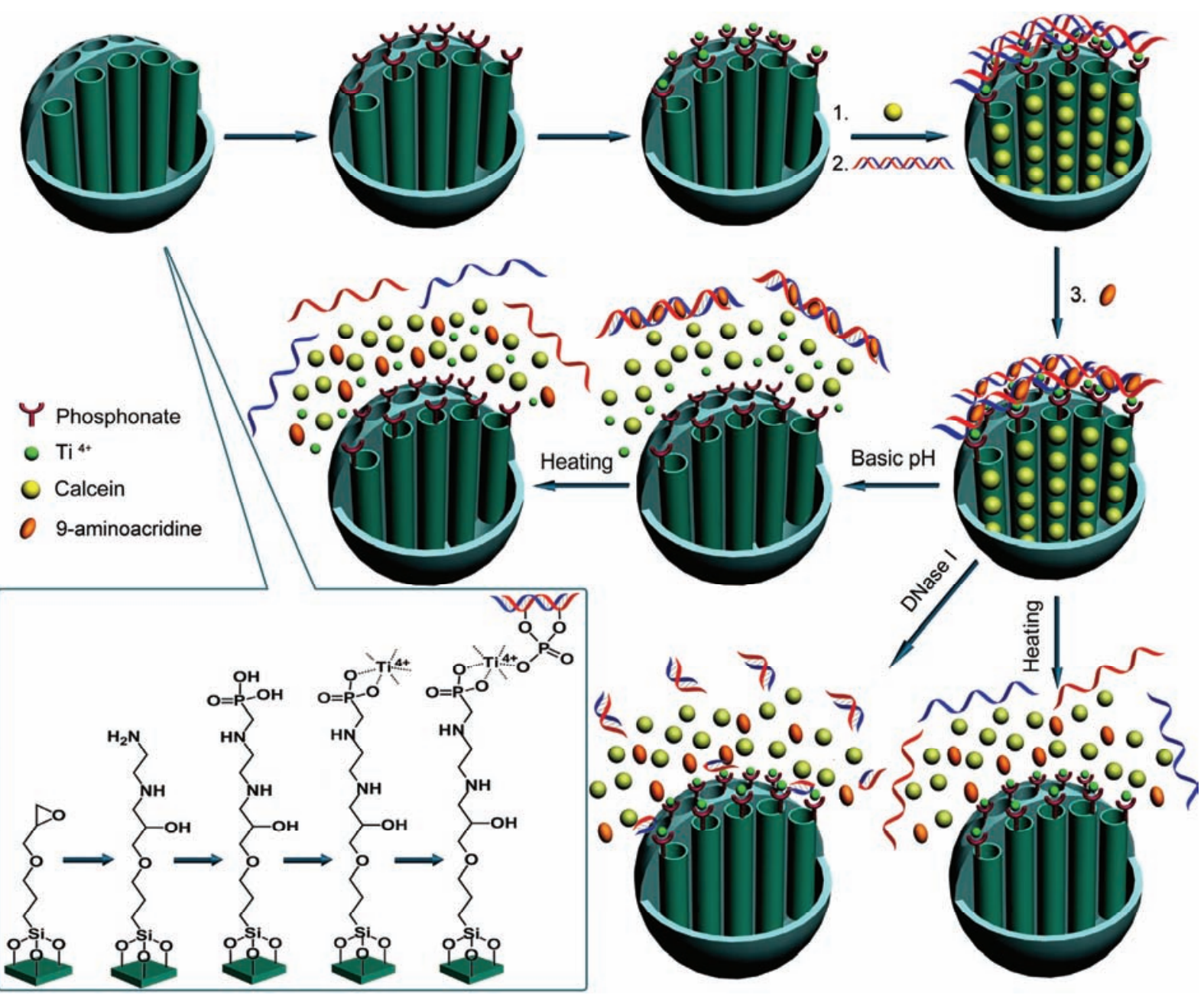

图 6 (网络版彩色) $\mathrm{DNA}$ 门控的 $\mathrm{Ti}^{\mathrm{IV}}$ 配位膦酸功能化的MSN纳米双载药系统的可控组装及封装在MSN纳米孔道的钲黄绿素和嵌插结合双链 DNA的呋啶胺的同时和连续控制释放 ${ }^{[50]}$

Figure 6 (Color online) Construction of DNA-gated MSN drug delivery systems functionalized with $\mathrm{Ti}^{\mathrm{IV}}$-chelating phosphonates for simultaneous and cascade release of calcein encapsulated in the MSN pores and acridinamine intercalating within duplex DNA ${ }^{[50]}$

后, 经3次近红外光照(每次 $10 \mathrm{~min}$ ), 然后再孵化 $24 \mathrm{~h}$, 仍然显示低的细胞毒性. 相应的DNA门控的 $\mathrm{Ti}^{\mathrm{I}}{ }^{\mathrm{I}}$ 配位 膦酸功能化的GNR@MSN纳米双载药系统则表现出 显著的抗增殖活性, 将肿瘤细胞的存活率降低至不 足 $6 \%$, 这是由于光热效应和光热引起两种药物同时 释放所致. 激光共聚焦显微镜观察显示, 在近红外光 照后两种药物在细胞内才发生明显释放 ${ }^{[50]}$. 结合近 红外光热治疗和刺激响应的化学治疗 (光热-化学治 疗), 可以实现治疗效果最大化.

\section{2 其他介孔结构纳米载药系统}

相较于MCM-41型MSN, 中空MSN(HMSN)是由 中间空腔和介孔结构的壳层构成的多级结构. HMSN
拥有更大的孔体积，可以装载更多的药物分子，从而 明显提高药物的装载量. 由于壳层的纳米孔道通过 中间的空腔相互连通, 原则上, 只要有一个纳米孔道 未被覆盖, 装载的药物分子就可以通过这个孔道渗 漏出来 ${ }^{[51]}$. 如何减少这种中空MSN纳米载药系统的 药物的前释放, 是一项相对艰难的工作. HMSN经氨 丙基三甲氧基硅烷修饰, 然后与二硫代二丙酸通过 酰胺键连结, 装载阿霉素药物, 氨基化的 $\mathrm{ZnO}$ 量子点 通过酰胺键连接到功能化的HMSN表面, 可控组装 $\mathrm{ZnO}$ 量子点门控的 $\mathrm{HMSN}$ 纳米载药系统, 使药物的前 释放降至最低 ${ }^{[52]}$. 在 $\mathrm{pH}$ 小于 $5.5, \mathrm{ZnO}$ 量子点被溶解 成 $\mathrm{Zn}^{\mathrm{II}}{ }^{\text {离子 }}{ }^{[53]}$, 导致纳米门被打开, 阿霉素药物被释 放出来 ${ }^{[52]}$. 在中性条件下, 加人二硫还原剂 $(\mathrm{GSH}$ 或 
DTT), 断裂二硫键, 使 $\mathrm{ZnO}$ 量子点脱离 $\mathrm{HMSN}$ 表面, 药物也能被释放出来 ${ }^{[52]}$. 不载药的 $\mathrm{ZnO}$ 量子点门控 的HMSN与A549细胞孵化72 h 后显示较低的细胞毒 性, 而装载阿霉素的纳米载药系统将肿瘤细胞的存 活率降至 $35 \%$ 左右 ${ }^{[53]}$, 该纳米载药系统在肿瘤药物 治疗方面具有潜在的应用前景. 此外, $\mathrm{ZnO}$ 量子点的 苂光成像能够用于示踪纳米载药系统在体内的输送 过程.

介孔碳纳米粒子 $(\mathrm{MCN})$ 具有类似 MSN的结构特 征和性质, 显示更低的生物毒性 ${ }^{[54]}$, 但一般疏水性 较强. 目前, 文献报道的刺激响应的门控 $\mathrm{MCN}$ 纳米 载药系统的研究工作还很少. 以具有两套相互独立 的三维螺旋孔道网络结构的 MCM-48型MSN为硬模 板, 制备具有三维交叉孔道结构的 $\mathrm{MCN}^{[55]}$. $\mathrm{MCN}$ 首 先经过羧基化处理, 再通过酰胺键连接最终实现氨 基化表面修饰, 羧基化修饰的 $\mathrm{ZnO}$ 量子点通过酰胺 键连接到氨基化的 $\mathrm{MCN}$ 表面, 可控组装 $\mathrm{ZnO}$ 量子点 门控的 $\mathrm{MCN}$ 纳米载药系统, 将罗丹明 $6 \mathrm{G}$ 或肿瘤药物 米托蒽醌封装于相互连通的纳米孔道中 ${ }^{[56]}$. 同样地, 在 $\mathrm{pH}$ 小 $5.5, \mathrm{ZnO}$ 量子点被溶解成 $\mathrm{Zn}$ 离子, 导致纳 米门被打开, 药物被释放出来, 同时升高温度对药物 释放也有促进作用 ${ }^{[56]}$. 不载药的 $\mathrm{ZnO}$ 量子点门控的 $\mathrm{MCN}$ 与 A549细胞孵化 $48 \mathrm{~h}$ 后显示较低的细胞毒性, 而装载米托葱醌的纳米载药系统将肿瘤细胞的存活 率降至35\%左右, 进一步通过激光共聚焦显微镜观 察药物在细胞内的释放行为 ${ }^{[56]}$, 该纳米载药系统在 肿瘤药物治疗方面具有潜在的应用前景.

\section{3 结论和展望}

生物相容性的 MSN作为新一代药物载体, 由于 独特的介孔结构和表面容易修饰的性质, 用于可控 组装刺激响应的MSN纳米载药系统, 实现药物控制 释放. 有效提高药物的治疗效果, 尽量降低药物的毒 副作用. 尽管国内外学者在刺激响应的MSN纳米载 药系统的研究方面已经取得重要进展, 但仍然面临 一些困难和挑战, 需要进一步的科学研究. 即使对于 体外实验, 文献报道的一些MSN纳米载药系统还存 在明显的药物前释放问题, 需要在环境响应的功能 基元设计和纳米载药系统的可控组装方面做出更多 努力. 最终将刺激响应的MSN纳米载药系统实际应 用到人体, 还有很长的路要走. 进一步的研究需要证 实, 在人体内复杂的生理环境下, 可控组装的 MSN 纳米载药系统可以将有效剂量的药物靶向输送到病 变细胞, 并在病变细胞的特定微环境条件下实现刺 激响应的药物控制释放, 达到个体化治疗的目的. 此 外, 科学工作者还需要致力于研发新型介孔纳米材 料作为药物载体, 例如: 相对稳定且最终可降解的介 孔材料、嵌人近红外光热转换的纳米粒子和/或苂光 发射的纳米粒子的介孔复合材料等. 新型介孔材料 应具备生物相容性、大的孔体积、水热稳定性、易于 功能化修饰和生物降解性, 用于纳米载药系统的可 控组装和刺激响应药物控制释放. 通过苂光成像示 踪纳米载药系统在体内的输送过程, 结合化学药物 治疗和近红外光热治疗等, 最大限度地提高肿瘤等 疾病的治疗效果.

\section{参考文献}

1 Slowing I I, Vivero-Escoto J L, Wu C W, et al. Mesoporous silica nanoparticles as controlled release drug delivery and gene transfection carriers. Adv Drug Deliver Rev, 2008, 60: 1278-1288

2 Chen C, Geng J, Pu F, et al. Polyvalent nucleic acid/mesoporous silica nanoparticle conjugates: Dual stimuli-responsive vehicles for intracellular drug delivery. Angew Chem Int Ed, 2011, 50: 882-886

3 Mura S, Nicolas J, Couvreur P. Stimuli-responsive nanocarriers for drug delivery. Nat Mater, 2013, 12: 991-1003

4 Coti K K, Belowich M E, Liong M, et al. Mechanised nanoparticles for drug delivery. Nanoscale, 2009, 1: 16-39

5 Popat A, Hartono S B, Stahr F, et al. Mesoporous silica nanoparticles for bioadsorption, enzyme immobilisation, and delivery carriers. Nanoscale, 2011, 3: 2801-2818

6 Ambrogio M W, Thomas C R, Zhao Y L, et al. Mechanized silica nanoparticles: A new frontier in theranostic nanomedicine. Acc Chem Res, 2011, 44: 903-913

7 Yang P P, Gai S L, Lin J. Functionalized mesoporous silica materials for controlled drug delivery. Chem Soc Rev, 2012, 41: 3679-3698

8 Coll C, Bernardos A, Martinez-Manez R, et al. Gated silica mesoporous supports for controlled release and signaling applications. Acc Chem Res, 2013, 46: 339-349

9 Argyo C, Weiss V, Brauchle C, et al. Multifunctional mesoporous silica nanoparticles as a universal platform for drug delivery. Chem 
Mater, 2014, 26: 435-451

10 Chen Y, Chen H R, Shi J L. Inorganic nanoparticle-based drug codelivery nanosystems to overcome the multidrug resistance of cancer cells. Mol Pharmaceut, 2014, 11: 2495-2510

11 Luo G F, Chen W H, Zhuo R X, et al. The design and application of functionalized mesoporous silica nanocarrier (in Chinese). Chin Sci Bull，2015，60：1104-1124 [雒国凤，陈巍海，卓仁禧，等. 功能化介孔硅纳米载体的设计及其应用。科学通报，2015，60: 1104-1124]

12 Du X. Biomacromolecule-gated mesoporous silica drug delivery systems for stimuli-responsive controlled release. In: Tiwari A, Patra H K, Choi J W, eds. Advanced Theranostics Materials. Salem: Scrivener Publishing LLC, 2015. 67-92

13 Aznar E, Oroval M, Pascual L, et al. Gated materials for on-command release of guest molecules. Chem Rev, 2016, 116: 561-718

14 Nguyen T D, Liu Y, Saha S, et al. Design and optimization of molecular nanovalves based on redox-switchable bistable rotaxanes. J Am Chem Soc, 2007, 129: 626-634

15 Yang Y W, Sun Y L, Song N. Switchable host-guest systems on surfaces. Acc Chem Res, 2014, 47: 1950-1960

16 Song N. Yang Y W. Molecular and supramolecular switches on mesoporous silica nanoparticles. Chem Soc Rev, 2015, 44: 3474-3504

17 Lagona J, Mukhopadhyay P, Chakrabarti S, et al. The cucurbit[n]uril family. Angew Chem Int Ed, 2005, 44: 4844-4870

18 Hennig A, Bakirci H, Nau W M. Label-free continuous enzyme assays with macrocycle-fluorescent dye complexes. Nat Methods, 2007, 4: $629-632$

19 Liu J, Du X. pH- and competitor-driven nanovalves of cucurbit[7]uril pseudorotaxanes based on mesoporous silica supports for controlled release. J Mater Chem, 2010, 20: 3642-3649

20 Russell D, Snyder S H. Amine synthesis in rapidly growing tissues-ornithine decarboxylase activity in regenerating rat liver chick embryo and various tumors. Proc Natl Acad Sci USA, 1968, 60: 1420-1427

21 Gerner E W, Meyskens F L Jr. Polyamines and cancer: Old molecules, new understanding. Nat Rev Cancer, 2004, 4: 781-792

22 Liu J, Du X, Zhang X. Enzyme-inspired controlled release of cucurbit[7]uril nanovalves by using magnetic mesoporous silica. Chem Eur J, 2011, 17: 810-815

23 Ogoshi T, Kanai S, Fujinami S, et al. para-Bridged symmetrical pillar[5]arenes: Their Lewis acid catalyzed synthesis and host-guest property. J Am Chem Soc, 2008, 130: 5022-5023

24 Ogoshi T, Hashizume M, Yamagishi T A, et al. Synthesis, conformational and host-guest properties of water-soluble pillar[5]arene. Chem Commun, 2010, 46: 3708-3710

25 Yu G, Xue M, Zhang Z, et al. A water-soluble pillar[6]arene: Synthesis, host-guest chemistry, and its application in dispersion of multiwalled carbon nanotubes in water. J Am Chem Soc, 2012, 134: 13248-13251

26 Xue M, Yang Y, Chi X, et al. Pillararenes, a new class of macrocycles for supramolecular chemistry. Acc Chem Res, 2012, 45: $1294-1308$

27 Huang X, Du X. Pillar[6]arene-valved mesoporous silica nanovehicles for multiresponsive controlled release. ACS Appl Mater Interfaces, 2014, 6: 20430-20436

28 Park C, Oh K, Lee S C, et al. Controlled release of guest molecules from mesoporous silica particles based on a pH responsive polypseudorotaxane motif. Angew Chem Int Ed, 2007, 46: 1455-1457

29 Wang C, Li Z X, Cao D, et al. Stimulated release of size-selected cargos in succession from mesoporous silica nanoparticles. Angew Chem Int Ed, 2012, 51: 5460-5465

30 Zhou S, Sha H, Ke X, et al. Combination drug release of smart cyclodextrin-gated mesoporous silica nanovehicles. Chem Commun, 2015, 51: 7203-7206

31 Lee J, Lee J, Kim S, et al. Sugar-induced release of guests from silica nanocontainer with cyclodextrin gatekeepers. Bull Korean Chem Soc, 2011, 32: 1357-1360

32 Qiu X L, Li Q L, Zhou Y, et al. Sugar and pH dual-responsive snap-top nanocarriers based on mesoporous silica-coated $\mathrm{Fe}_{3} \mathrm{O}_{4} \mathrm{magnetic}$ nanoparticles for cargo delivery. Chem Commun, 2015, 51: 4237-4240

33 Matsumoto A, Ishii T, Nishida J, et al. A synthetic approach toward a self-regulated insulin delivery system. Angew Chem Int Ed, 2012, 51: 2124-2128

34 Ma R, Shi L. Phenylboronic acid-based glucose-responsive polymeric nanoparticles: synthesis and applications in drug delivery. Polym Chem, 2014, 5: 1503-1518

35 Yang B, Jia H, Wang X, et al. Self-assembled vehicle construction via boronic acid coupling and host-guest interaction for serum-tolerant DNA transport and pH-responsive drug delivery. Adv Healthcare Mater, 2014, 3: 596-608

36 Schlossbauer A, Kecht J, Bein T. Biotin-avidin as a protease-responsive cap system for controlled guest release from colloidal mesoporous silica. Angew Chem Int Ed, 2009, 48: 3092-3095 
37 Smith E A, Thomas W D, Kiessling L L, et al. Surface plasmon resonance imaging studies of protein-carbohydrate interactions. J Am Chem Soc, 2003, 125: 6140-6148

38 Becker J W, Reeke G N Jr, Cunningham B A, et al. New evidence on location of saccharide-binding site of concanavalin-A. Nature, 1976, 259: 406-409

39 Wu S, Huang X, Du X. Glucose- and pH-responsive controlled release of cargo from protein-gated carbohydrate-functionalized mesoporous silica nanocontainers. Angew Chem Int Ed, 2013, 52: 5580-5584

40 Zheng H, Du X. Enhanced binding and biosensing of carbohydrate-functionalized monolayers to target proteins by surface molecular imprinting. J Phys Chem B, 2009, 113: 11330-11337

41 Zheng H, Du X. Protein-directed spatial rearrangement of glycolipids at the air-water interface for bivalent protein binding: In situ infrared reflection absorption spectroscopy. J Phys Chem B, 2010, 114: 577-584

42 Zheng H, Du X. Multivalent protein binding in carbohydrate-functionalized monolayers through protein-directed rearrangement and reorientation of glycolipids at the air-water interface. Biochim Biophys Acta, 2011, 1808: 2128-2135

43 Zheng H, Du X. Reduced steric hindrance and optimized spatial arrangement of carbohydrate ligands in imprinted monolayers for enhanced protein binding. Biochim Biophys Acta, 2013, 1828: 792-800

44 Maloney K M, Schief W R Jr, Pack D W, et al. Binding and two-dimensional crystallization of streptavidin at the air/water interface via engineered Cu-IDA chelator lipids. Coord Chem Rev, 1999, 183: 3-18

45 Kent M S, Yim H, Sasaki D Y, et al. Analysis of myoglobin adsorption to Cu(II)-IDA and Ni(II)-IDA functionalized Langmuir monolayers by grazing incidence neutron and X-ray techniques. Langmuir, 2004, 20: 2819-2829

46 Wang X, Huang X, Xin Y, et al. Myoglobin-directed assemblies of binary monolayers functionalized with iminodiacetic acid ligands at the air-water interface through metal coordination for multivalent protein binding. Phys Chem Chem Phys, 2012, 14: 5470-5478

47 Wu S, Deng Q, Huang X, et al. Synergetic gating of metal-latching ligands and metal-chelating proteins for mesoporous silica nanovehicles to enhance delivery efficiency. ACS Appl Mater Interfaces, 2014, 6: 15217-15223

48 Zhou S, Du X, Cui F, et al. Multi-responsive and logic controlled release of DNA-gated mesoporous silica vehicles functionalized with intercalators for multiple delivery. Small, 2014, 10: 980-988

49 Zhou H, Ye M, Dong J, et al. Robust phosphoproteome enrichment using monodisperse microsphere-based immobilized titanium (IV) ion affinity chromatography. Nat Protoc, 2013, 8: 461-480

50 Zhou S, Sha H, Liu B, et al. Integration of simultaneous and cascade release of two drugs into smart single nanovehicles based on DNA-gated mesoporous silica nanoparticles. Chem Sci, 2014, 5: 4424-4433

51 Du L, Liao S, Khatib H A, et al. Controlled-access hollow mechanized silica nanocontainers. J Am Chem Soc, 2009, 131: 15136-15142

52 Wu S, Huang X, Du X. pH- and redox-triggered synergistic controlled release of a ZnO-gated hollow mesoporous silica drug delivery system. J Mater Chem B, 2015, 3: 1426-1432

53 Muharnmad F, Guo M, Qi W, et al. pH-triggered controlled drug release from mesoporous silica nanoparticles via intracelluar dissolution of ZnO nanolids. J Am Chem Soc, 2011, 133: 8778-8781

54 Yan A H, Lau B W, Weissman B S, et al. Biocompatible, hydrophilic, supramolecular carbon nanoparticles for cell delivery. Adv Mater, 2006, 18: 2373-2378

55 Gu J L, Su S S, Li Y S, et al. Hydrophilic mesoporous carbon nanoparticles as carriers for sustained release of hydrophobic anti-cancer drugs. Chem Commun, 2011, 47: 2101-2103

56 Huang X, Wu S, Du X. Gated mesoporous carbon nanoparticles as drug delivery system for stimuli-responsive controlled release. Carbon, 2016, 101: 135-142 


\title{
Controlled assemblies of stimuli-responsive mesoporous silica drug delivery systems for controlled release of drugs
}

\author{
DU XueZhong \\ Key Laboratory of Mesoscopic Chemistry (Ministry of Education), School of Chemistry and Chemical Engineering, Nanjing University, Nanjing \\ 210023, China \\ E-mail: xzdu@nju.edu.cn
}

There has been an ever increasing interest in developing stimuli-responsive mesoporous silica drug delivery systems to improve therapeutic efficacy and minimize the adverse effects of drugs. This paper reports the works of our research group on valved and gated mesoporous silica drug delivery systems. Biocompatible mesoporous silica nanoparticles (MSNs), as drug carriers, were modified with active group-terminated silanes via self-assembly followed by diverse functionalization, a variety of macrocyclic hosts, proteins, DNA, and quantum dots were bound to the MSN surfaces to develop nanovalves and nanogates, through multiple noncovalent interactions, dynamic covalent bonds, and even strong covalent bonds, for the encapsulation of drugs within MSN pores, thus smart valved and gated MSN drug delivery systems were constructed. Under the stimuli of $\mathrm{pH}$, redox, competitive binding, enzymes, and near infrared lights, controlled release of the encapsulated drugs was realized, because of the destruction of multiple noncovalent interactions, the cleavage of dynamic covalent bonds, and the disassociation of gatekeeping scaffolds. The carboxylate-substituted pillar[6]arene (CPA[6])-valved dimethylbenzimidazolium or bipyridinium-functionalized MSN drug delivery systems were constructed for acidic $\mathrm{pH}$, competitive binding, and metal chelating-responsive controlled release. The $\gamma$-CD-gated MSN delivery system functionalized with disulfide-linked carbamoylphenylboronic acid moieties and amines via dual dynamic covalent bonds with dual drug loading was constructed for simultaneous and cascade release of two drugs. It is a smart strategy to take advantage of the specific structures and properties of cyclodextrins (CDs) for use in the MSN drug delivery systems not only as gatekeepers but also as drug carriers. The $\gamma$-CD-gated MSN delivery system provided a smart platform for combination drug therapy, in addition to resistance to serum and normal blood glucose levels. The concanavalin A (Con A)-gated mannose-functionalized MSN drug delivery system via multivalent carbohydrate-protein interactions was constructed for the controlled release of drugs either by acidic $\mathrm{pH}$ or by competitive binding of glucose at high concentrations. The long and flexible spacers linked with the mannose ligands played an important role in adjusting the local spatial arrangement of the ligands to favor multivalent protein binding, as did the surface density of the ligands. The MSN drug delivery systems functionalized with $N$-(3-trimethoxysilylpropyl)ethylenediamine triacetate ligands, in the presence of metal ions with and without myoglobin containing surface-accessible histidine residues, were constructed for $\mathrm{pH}$-responsive controlled release. Both the metal-latching ligands and the metal-chelating proteins played a synergetic role in gating MSNs for high-loading drug delivery and stimuli-responsive controlled release. The DNA-gated MSN drug delivery system functionalized with disulfide-linked acridinamine intercalators was constructed for multi-responsive controlled release under different stimuli, including disulfide reducing agents, elevated temperature, and deoxyribonuclease I. The DNA-gated MSN drug delivery system integrated multiple responses and AND logic gate operations into a single smart nanodevice not only for codelivery of drugs and DNA/genes but also for cascade release of two drugs in combination of dual stimuli. The DNA-gated gold nanorod-embedded MSN delivery system functionalized with titanium(IV)-chelating phosphonates with dual drug loading was constructed for simultaneous and cascade release of two drugs. Coordination chemistry is the first strategy for DNA cappings through multivalent chelating interactions in drug delivery systems not only as gatekeepers but also as drug carriers. The two drugs were simultaneously released upon triggering of endonuclease degradation or photothermal dehybridization and were successively released upon first triggering of basic $\mathrm{pH}$ and subsequent triggering of photothermal heating. The combination of NIR light-based thermotherapy and triggered chemotherapy (thermo-chemotherapy) could maximize therapeutic efficacy. In addition, the $\mathrm{ZnO}$ quantum dot $(\mathrm{QD})$-gated hollow mesoporous silica drug delivery system was constructed for $\mathrm{pH}$ and redoxresponsive controlled release, and the $\mathrm{ZnO} \mathrm{QD}$-gated mesoporous carbon nanoparticle (MCN) drug delivery system was for $\mathrm{pH}$-responsive controlled release. These constructed stimuli-responsive MSN drug delivery systems have promising applications in targeted tumor therapy.

mesoporous silica drug delivery system, nanovalve, nanogate, stimuli-response, controlled release

doi: 10.1360/N972016-00409 